Marquette University

e-Publications@Marquette

$12-1-2010$

\title{
A Decision Model for E-commerce-enabled Partial Market Exit
}

Siddhartha Syam

Marquette University, siddhartha.syam@marquette.edu

Amit Bhatnagar

University of Wisconsin - Milwaukee

Post-print. Journal of Retailing, Volume 86, No. 4 (December 2010), DOI. (C) Elsevier 2010. Used with permission. 


\section{A Decision Model for E-commerce-enabled Partial Market Exit}

By Siddhartha Syam and Amit Bhatnagar

Struggling retail chains often try to recover profitability by closing some of their stores. The challenge in this strategy lies in determining how many stores to close, as store exit has implications for both the customers and the supply chain. After a store closes, its customers are lost forever to the competition, unless there is a surviving open store nearby or an electronic alternative such as an e-store. From the supply chain perspective, after a store closes, its supporting regional distribution center is left with less business, and thus reduced viability. This paper develops a decision support model to study the profitability of alternative retail network structures by varying the proportion of stores that are closed, the average price sensitivity of demand, the price difference between the online store and the traditional retailers, and customer retention rates.

\section{Introduction}

While the current slowdown in economy has different implications for different sectors of economy, the implication for retailers is that it invariably leads to closing of stores. In just the last two months of 2008, a number of venerable retail chains, such as Circuit City, Steve \& Barry's, Tweeter, Club Libby Lu, Whitehall Co. Jewelers, Mervyn's, CompuUSA, etc. filed for bankruptcy and exited the market. Therefore, while store closing is very real, little academic research has been carried out to examine the different facets of store closing.

Furthermore, the limited research on market exit (Dixit and Chintagunta 2007; Karakaya 2000; Murto 2004; Ping 1999) has examined only two decision choices for a firm, to exit or to stay. In practice, there exists a third option of partial exit by a retail firm, for example, a chain store can close some stores, and retain others. Partial market exit as a strategy is often pursued by struggling retail firms to recover profitability. Consider the following instances from the last quarter of 2008. On January 8,2009 , after reporting a $\$ 30$ million loss in the first nine months of 2008 , and with sales dropping 4.3\%, Macy announced the closure of eleven stores. On December 10,2008, office supply chain Office Depot said that it would shutter 112 stores over the next three months as part of an effort to cut costs amid a slumping economy. In November 2008, Sears announced the closure of eight underperforming stores. Some other major retail chains that partially exited the market in $\mathbf{2 0 0 8}$ are Sharper Image, Talbots, Eddie Bauer, Ann Taylor, Linens ' $n$ Things, Gap Inc., Foot Locker, KB Toy Works, Jasmine Sola, Zale Corp, 
Bombay Company, Pier 1, Walt Disney Stores, Home Depot, Pep Boys, Sprint Nextel, Ethan Allen Interiors, Verizon, Home Depot, Lowes, etc. Partial market exit as a strategy need not be confined to only retail chains, but can be deployed by any member of the distribution channel. For instance, in 2007, Bon-Ton Department store closed one of its distribution centers and consolidated its merchandise processing functions into its four remaining distribution centers (FinancialWire 2007). Surprisingly, despite being so common, partial exit has received no attention from academic researchers.

One would expect a retail chain pursuing partial market exit to close the poor performing stores and retain the high-performing ones. However, the choice of stores to close is complicated by the fact that store closing has implications for the customers of the closed store. Customers of closed stores suffer from a feeling of abandonment and may be forever lost to the competition (Johnson 2000). A retail firm can use its surviving retail stores to retain the customers of closed stores (see Exhibit 1). Travel to these more distant stores involves extra travel cost for the customers, making the distant stores less attractive than the closed store. Therefore, while deciding whether to close a store, it is critical to ensure that there is a surviving store within a reasonable distance, so as not to impose too high a travel cost on its customers. In recent years, this constraint has been mitigated to some extent by the emergence of the Internet which makes it possible for firms to retain some of the lost sales via an online store. The idea of using multiple channels to retain consumer loyalty has been examined by Wallace, Giese and Johnson (2004). Total migration from the closed store to the Internet is rare, as an Internet-based store is also not a perfect substitute for a bricks-and-mortar store due to factors such as shipping costs, and privacy and online security risks faced by consumers. Since neither the surviving stores nor the online store are perfect substitutes for the closed store, there is always some attrition of sales to the competition. As customer retention is crucial for financial success, it follows that it is important to minimize this attrition of customers to the competition when deciding which stores to close and which to leave open. Another factor that complicates the choice of stores to close is the implications of store closing for the supply chain that services the store. Just as stores may have to be closed because of insufficient sales, regional distribution centers (RDCs) may have to be closed because of an insufficient number of stores to service. However, if an RDC closes, the surviving stores that were being supported by this RDC will now have to be supported by one of the surviving RDCs. This increases the processing load on the surviving RDCs, in addition to increasing the transportation cost from the more distant RDCs to the surviving stores. It is important that all these consequences of store closing for the supply chain should be factored into a decision support model for store closing. 
The issues that we have identified above have been incorporated into our decision support model which is developed to guide a retail firm in redesigning its retail network by closing some of its traditional stores and replacing them by an online store. Specifically, the integer-programming model can determine the optimal number of stores and RDCs to close. The model accomplishes this by establishing the combination of open stores and RDCs at which the system profitability is the highest. While determining the profitability of the system, we consider the total revenue and the various applicable logistical costs. In order to evaluate how different factors impact profitability, we conducted a managerial experiment by varying the proportion of stores that are closed, the price sensitivity of demand of products, the discount offered by the online retailer, and the demand retention rate.

Extant research in market exit has employed either analytical models (Murto 2004) or empirical models (Dixit and Chintagunta 2007). In this paper, we developed an integer-programming (IP) model to study the issue of partial market exit. In the past, IP models have been used to study department-level promotion-mix planning (Allaway, Mason and Brown 1987), seasonal merchandizing planning (Smith, Agrawal, and Mclntyre 1998), potential franchise sites for their impact on distribution system revenue and on existing outlets (Ghosh and Craig 1991), potential retail location sites for their impact on market share (Drezner 1994), etc.

The chief contribution of our paper to the under-researched area of market exit (Dixit and Chintagunta 2007) is that we consider partial market exit from a traditional channel in combination with entry into the online channel. Our model allows for partial market exit by all kinds of intermediaries in the distribution channel - retailers, distribution centers, etc. Our second contribution is that we identify a number of factors that would influence the level of partial exit, and incorporate these factors in our model. Our third point of departure from extant studies is that instead of treating the online and offline channels as competitive, we treat them as complementary in the sense that retail chains use the online channel to retain the customers of a closed store. The organization of the rest of the paper is as follows. The next section reviews the relevant literature. In 'A general model' section, we discuss the mathematical formulation of the problem and solution approach. In the following section, we present the numerical results and managerial analysis. This is followed by the Section 'Concluding remarks'.

\section{Literature Review}

In this section, we review three streams of literature. The first stream of literature reviews the published studies on store mortality and market exit. The second stream of literature relates to models of competition between the traditional and online channels. The third stream of 
literature surveys the relevant research from the supply chain area.

Store mortality drew some interest from researchers during the first half of the last century (Burd 1941; Greer 1936; McGarry 1947; Phillips 1934). These studies were more in the nature of surveys of store mortality rates in different cities, such as Boston (Phillips 1934), Buffalo and Pittsburgh (1947), Seattle (Burd 1941), etc., and did not analyze in a systematic fashion the causes and consequences of store mortality. In a study of seventeen, 252 stores over a five-year period, Star and Massel (1981) found that only 33.2\% survived at the end of five years. According to Star and Massel, this rate has remained constant since World War II. Therefore, it is very surprising that while store mortality is a fact of retail life, academic research into its causes and consequences is virtually non-existent.

Grewal and Levy (2009) have identified the growth of the Internet and e-commerce as one of the four research areas with the potential for the greatest contribution to retailing research. Therefore, it is not surprising that a number of researchers have studied the competition between the traditional channel and the online channel (Ansari, Mela and Neslin 2008; Laroche et al. 2005; Konus, Verhoef and Neslin 2008; Chiang, Chhajed and Hess 2003; Kwon and Lennon 2009; Pentina, Pelton and Hasty 2009; Tang and Xing 2001). For instance, Tang and Xing (2001) found that online stores of multichannel retailers are unable to lower their prices because they have to take into account the impact that such actions will have on their brick and mortar stores (hereafter, they will be called BM stores). In the retail climate that we investigate, the online channel generally complements the traditional channel by allowing the retail chain to retain at least some of the customers of the closed stores. Consumer acceptance of the online channel is less than that of the traditional channel (Chiang, Chhajed and Hess 2003) and that is why not all the customers of a closed store migrate to the online store.

Aksen and Altinkemer (2008) and Bendoly et al. (2006) have studied the issue of multichannel competition from the supply side. Aksen and Altinkemer (2008) studied the distribution logistics of a hybrid clicks and bricks model. Their location-routing model incorporates clicks and mortar stores to meet the demand of both walk-in and online customers, and a quality of service guarantee for online customers based on the timely delivery of orders. Bendoly et al. (2006) developed a model to investigate the total cost ramifications of inventory allocation strategies while maintaining customer service levels. They consider a two-echelon fixed period inventory system, with the goal of minimizing total cost while maintaining a service level goal. The conclusions of their research indicate that the proportion of a firm's demand satisfied online is an important factor affecting the decision to centralize or decentralize online inventory. They also find that there is a threshold online demand percentage, below which 
decentralization is the preferred strategy.

While researchers in marketing study the problem of hybrid retailing from the demand side, researchers in supply chain management and operations management examine the problem from the supply side. Study of the role of supply chain on retailer performance is something new and has been recognized as one of the emerging trends in retailing research (Dong, Shanker and Dresner 2007; Ganesan et al. 2009).

\section{A General Model}

In this section, we build a very general model of the market. The model is built from the perspective of a retail chain that intends to maximize its overall profit by closing some of the traditional BM stores and migrating the customers of the closed stores to its online store as well as the nearest open BM store. Since an online store is not a perfect substitute of a BM store, it is expected that not all customers of a closed BM store will migrate to the online store (We do not consider the special case of purely digital goods, where an online store is clearly superior to a BM store). Some of the customers of the closed BM store will travel a greater distance to the nearest BM store that stays open and some others will simply switch to the competition. The primary decision that the retailer is concerned with is the number (and, by implication, the proportion) of stores to close. A secondary decision is to determine the number of RDCs to close.

The model is fairly complex and we had to make some simplifying assumptions to keep it tractable. These include the following: (a) the model is static rather than dynamic and does not consider change over time periods (b) the model is deterministic which implies that data variation over a single time period is small enough that the complexity of a stochastic approach is not warranted (c) we assume that the relevant data is fully available to the firm (d) the demand functions that relate price to demand are known and (e) the relevant cost functions and constraints of the firm have been identified.

The retail chain has $N$ BM stores. These $N$ stores are supported by $M$ RDCs that are also owned by the retail chain. In addition to supporting the stores, the RDCs may also sell directly to the customers. Each store carries $I$ number of items. The retail chain subsequently withdraws NCLS number of BM stores from the market, and replaces them with an online store. After NCLS BM stores exit, some of the RDCs also are forced to exit and only NODC number of RDCs remain open. The open BM stores are indexed by $n$, closed BM stores by $k$, the online store by $o$, and the RDCs by $m$.

Let $p_{i k}$ be the price of item $i$ at closed BM store $k$ of a chain. Some of the customers of this closed store will now travel to a more distant open BM store $n$ of the chain, and 
consequently incur an extra travel cost $t s^{k n}$. This extra travel cost depends on the specific distance between a particular pair of stores, and is therefore indexed by the superscript $k n$. The travel cost can be considered to be a fixed charge per trip made by the customer. Therefore, we prorate this fixed cost over the expected number of items (which could be multiple copies of the same item or diverse items) that the customer purchases per trip.

Referring to the expected number of items purchased as enp, the full price $p_{i}^{k n}$ borne by customers of closed store $k$ if they shop at the more distant store $n$ is:

$$
p_{i}^{k n}=p_{\text {in }}+\left(\frac{t s^{k n}}{e n p}\right)
$$

Some of the other customers of closed store $k$ will migrate to the online store. Products purchased online have to be shipped to the buyer's residence or site and therefore buyers incur a shipping charge $s c_{i}$ when they shop online. The shipping charge is generally common to customers at all locations (Balasubramanian 1998), but will depend on the weight of item $i$, and therefore the subscript $i$. The shipping surcharge will raise the online price $p_{i}^{k o}$ to $p_{i k}\left(1+s c_{i}\right)$. Brynjolfsson and Smith (2000) empirically compared the prices for homogeneous physical goods (CDs and books) at online and conventional stores over fifteen months, and found that prices were generally lower at the Internet stores. The lower prices have been partially explained by the efficiencies brought about by the emerging information technologies that have led to lower costs of operation (Bakos 1998). The lower prices on the Web may also be due to factors on the demand side. Bakos (1997) shows analytically that as buyer search costs fall, price competition among the sellers increases, and puts downward pressure on prices. We account for the lower price at the online store with the discount term $o d c_{i}$. Since the online price for a product is usually independent of where the customer is located, we compute the average price for a product and modify that in order to specify the online price for the product. Let the average price for the product over all stores be $p_{i}^{a}$. Using this average price, we specify the online price $p_{i}^{o}$ as, $p_{i}^{o}=p_{i}^{a}\left(1+s c_{i}\right)\left(1-o d c_{i}\right)$.

\section{Demand Functions}

We assume that $d m x_{i n}$ is the maximum possible demand for item $i$ corresponding to the minimum sustainable price of the product at open BM store $n$. The demand function for item $i$ at open store $n$ is modeled as a linear, decreasing function of price $p_{i n}$. Correspondingly, let $d s l p_{\text {in }}$ be the absolute value of the negative slope of the demand curve for item $i$ at store $\mathrm{n}$ and $\pi^{n}$ be the proportion of demand retained by an open BM store after the online channel is 
available. Then demand for an item at the open BM store can be specified as:

$$
d_{\text {in }}=\left(d m x_{i n}-d s l p_{i n} p_{i n}\right) \pi^{n}
$$

If RDCs sell directly to the customers, then the demand function $d_{i m}$ at an RDC is similar to the demand function of a store, except that the maximum demand is multiplied by a multiplier $m d_{m}$ that represents the generally higher level of sales at RDCs which, when sales are permitted, operate as regional superstores. If $\pi^{m}$ is the proportion of demand retained by an open RDC when the online channel is available, then demand for an item at the RDC can be specified as:

$$
d_{i m}=\left(m d_{m} d m x_{i m}-d s l p_{i m} p_{i m}\right) \pi^{m}
$$

The demand function $d_{i m}$ can be set to zero to eliminate RDC sales when these are not permitted.

When a BM store closes, some of its demand will be transferred to the online store, some of its demand to an open BM store, and the remainder will simply be lost to competitors. The transfer demand function $d_{i}^{k o}$ at the online store is the demand function at a (closed) bricks-and-mortar store based on the online transfer price multiplied by the online retention factor, $\pi^{o}$, which is generally less than one and equal to one only in the case of perfect retention. As mentioned previously, we assume that at the initial stage of partial market exit most of the demand at the online store comes from the customers of closed stores (in an experiment described later, we also investigate what happens if open BM stores lose significant market share to the online channel). Therefore, at this stage, the online store does not draw any sales from the competition, and, using notation analogous to that for the demand functions for a store:

$$
d_{i}^{k o}=\left(d m x_{i k}-d s l p_{i k} p_{i}^{o}\right) \pi^{o}
$$

To include the transfer demand from open BM stores to the online facility, we also have:

$$
d_{i}^{n o}=\left(d m x_{i n}-d s l p_{i n} p_{i}^{o}\right)\left(1-\pi^{n}\right)
$$

Next, the retention rate for demand transferred from a closed store to an open store is $\pi^{k}$,which is also less than or equal to one. It should be noted that we impose the condition: $\pi^{o}+\pi^{k} \leq 1$. This ensures that the combined demand transferred from a closed store to the online store and the nearby open store does not exceed the original closed store demand. The demand function $d_{i}^{k n}$ for an item that is transferred from a closed store to an open store is the demand function based on the store transfer price multiplied by the closed store retention factor: 


$$
d_{i}^{k n}=\left(d m x_{i k}-d s l p_{i k} p_{i}^{k n}\right) \pi^{k}
$$

As described earlier, the store transfer price includes the travel cost component prorated over the expected number of items the customer purchases per trip.

\section{Logistics Elements of the Model}

The retail network model developed in this paper maximizes profit which is a function of revenue from sales and costs that are mainly logistical in nature. The logistical elements incorporated into the model are those that are considered critical in logistical network planning as the following references illustrate. According to Simchi-Levi, Kaminsky and Simchi-Levi (2007), network planning is "the process by which the firm structures and manages the supply chain in order to find the right balance between inventory, transportation, and manufacturing costs". Further, they state that network design "includes decisions on the number, locations, and size of manufacturing plants and warehouses, the assignment of retail outlets to warehouses, and so forth". Chopra and Meindl (2007) believe "companies must consider inventory, transportation and facility costs when designing their supply chain networks...total logistics costs are a sum of the inventory, transportation, and facility costs".

The relative importance of these elements and the calibration of the model are interrelated. The relative weight of facility (fixed and variable) costs, inventory costs, and transportation costs within logistics costs is very much a function of factors such as the technology deployed by a particular company, and the freight mode(s) and distances, and the types of goods involved. For instance, a firm which uses advanced automated technology in store and/or warehouse operations and ships goods over long distances will incur relatively high fixed facility and transportation costs. The calibration of the model in this paper was done based on the data provided by a firm with which one of the authors had an advisory relationship. While this data has to be disguised due to confidentiality requirements, it is possible to state that this firm is in the retail hardware business and mainly uses an internally owned fleet for transportation. Further, it uses a medium level of technology in its operations (limited use of materials-handling machinery in warehouses, none in stores, and no advanced robotics). We outline the basic data used in our study in Appendix A. The parameters and variables of the model used to describe the objective function and constraints are shown in Table 1.

\section{Objective Function}

The retail chain maximizes the total profit made by its BM retailers, the online retailer, and 
RDCs. Each member of the retail chain, that is, $B M$ retailers, the online retailer, and $R D C s$ generates revenues from sales to consumers and incurs certain costs. The BM stores and RDCs incur fixed costs, variable costs, holding costs, and transportation costs. The online channel is viewed as a facilitator or intermediary between the suppliers, BM stores and RDCs. Thus it incurs only fixed costs and variable costs which, in the case of this study, are lower on a per unit basis than $B M$ stores and RDCs. In particular, the objective function that is maximized by the retail firm would consist of the following terms,

(1) Revenue of open BM stores

$$
\sum_{i \in I} \sum_{n \in N} d_{i n} p_{i n} \beta_{n}
$$

(2) Revenue of RDCs from direct sales to consumers. It should be noted that if direct sales to consumers at a RDC are not permitted, then all $d_{i m}$ are set to zero

$$
\sum_{i \in I} \sum_{m \in M} d_{i m} p_{i m} \alpha_{m}
$$

(3) Revenue due to sales transferred from (a) closed BM stores and (b) open BM stores respectively to the online store

$$
\sum_{i \in I} \sum_{k \in N} d_{i}^{k o} p_{i}^{o}\left(1-\beta_{k}\right)+\sum_{i \in I} \sum_{n \in N} d_{i}^{n o} p_{i}^{o} \beta_{n}
$$

(4) Revenue due to sales transferred from closed BM stores to open BM stores

$$
\sum_{i \in I} \sum_{k \in N, k \neq n} \sum_{n \in N} d_{i}^{k n} p_{i n} \varphi_{k n}
$$

(5) -Fixed cost at online store

$$
-F C_{o}
$$

(6) -Fixed costs at open BM stores

$$
-\sum_{n \in N} F C_{n} \beta_{n}
$$

(7) -Fixed costs at regional distribution centers

$$
-\sum_{m \in M} F C_{m} \alpha_{m}
$$

(8) -Variable cost at online store 
$-\sum_{i \in I} \sum_{k \in N} v c_{o} d_{i}^{k o} p_{i}^{o}\left(1-\beta_{k}\right)+\sum_{i \in I} \sum_{n \in N} v c_{o} d_{i}^{n o} p_{i}^{o} \beta_{n}$

(9) -Variable costs at regional distribution centers. The first term captures a RDC's variable costs due to direct sales to consumers and the second term captures variable costs due to supplying the open BM stores

$-\sum_{i \in I} \sum_{m \in M} \sum_{n \in N} v c_{m} e f_{m} d_{i m} p_{i m} \alpha_{m}+v c_{m} e f_{m} d_{i n} p_{i n} \varphi_{k n}$

(10) -Variable costs at RDCs due to sales transferred from closed stores

$\sum_{i \in I} \sum_{k \in N, k \neq n} \sum_{m \in M} \sum_{n \in N} v c_{m} e f_{m} d_{i}^{k n} p_{i n} \omega_{k m n}$

(11) -Variable costs of current sales at open BM stores

$-\sum_{i \in N} \sum_{n \in N} v c_{n} d_{i n} p_{i n} \beta_{n}$

(12) -Variable costs at open BM stores due to sales transferred from closed BM stores

$-\sum_{i \in I} \sum_{k \in N, k \neq n} \sum_{n \in N} v c_{n} d_{i}^{k n} p_{i n} \varphi_{k n}$

(13) - Holding costs of current sales at regional distribution centers

$-\left(\frac{1}{2}\right) \sum_{i \in I} \sum_{m \in M} \sum_{n \in N} d_{i n} p_{i n} h c_{i} e f_{m} \gamma_{m n}+d_{i m} e f_{m} p_{i m} h c_{i} \alpha_{m}$

(14) -Holding costs at RDCs due to sales transferred from closed BM stores

$-\left(\frac{1}{2}\right) \sum_{i \in I} \sum_{k \in N, k \neq n} \sum_{m \in M} \sum_{n \in N} d_{i}^{k n} p_{i n} e f_{m} h c_{i} \omega_{k m n}$

(15) -Holding costs of current sales at open BM stores

$-\left(\frac{1}{2}\right) \sum_{i \in I} \sum_{n \in N} h c_{i} d_{i n} p_{i n} \beta_{n}$

(16) -Holding costs at open BM stores due to sales transferred from closed BM stores $-\left(\frac{1}{2}\right) \sum_{i \in I} \sum_{k \in N, k \neq n} \sum_{n \in N} d_{i}^{k n} p_{i n} h c_{i} \phi_{k n}$ 
(17) -Transportation costs of current sales between RDCs and open BM stores

$-\sum_{i \in I} \sum_{m \in M} \sum_{n \in N} d i s t_{m n} d_{i n} t c_{i} w t_{i} \gamma_{m n}$

(18) -Transportation costs between RDCs and open BM stores due to sales transferred from closed BM stores

$-\sum_{i \in I} \sum_{k \in N, k \neq n} \sum_{m \in M} \sum_{n \in N} d_{i}^{k n} t c_{i} w t_{i} d i s t_{m n} \omega_{k m n}$

\section{Constraints}

The objective function above is maximized subject to the following constraints:

(1) Every open store is allocated to exactly one RDC, and closed stores cannot be allocated

$$
\sum_{m \in M} \gamma_{m n}=\beta_{n} \forall n
$$

(2) Every open store is allocated to an open RDC within distance limit

$\gamma_{m n} \operatorname{dist}_{m n} \leq \operatorname{DistRB} \alpha_{m} \forall m, n$

(3) Transfer from closed BM store must be to an open BM store

$\varphi_{k n} \leq \beta_{n} \forall k, \quad n: k \neq n$

(4) Transfer from closed BM store to only one open BM store

$\sum_{n \in N, k \neq n} \varphi_{k n}=1 \forall k$

(5) Transfer to open BM store must be from closed store within distance limit

$\varphi_{k n} \operatorname{dist}_{k n} \leq \operatorname{DistCB}\left(1-\beta_{k}\right) \forall k, \quad n: k \neq n$

(6) Transfer to RDC depends on closed store to open store assignment

$\omega_{k m n} \leq \varphi_{k n} \forall k, m, \quad n: k \neq n$

(7) Transfer to RDC depends on open store to RDC assignment

$\omega_{k m n} \leq \gamma_{m n} \forall k, m, \quad n: k \neq n$

(8) Number of closed stores parameter 


$$
\sum_{k \in K}\left(1-\beta_{k}\right)=N C L S
$$

(9) Number of open RDCs parameter

$$
\sum_{m \in M} \alpha_{m}=N R D C
$$

The number of variables (all binary) is: $M+N+M N+N^{2}+N^{2} M$. Thus, as an example, in our managerial experiment described in the following section the model has a total of 40 stores and 25 warehouses. Therefore, the number of binary variables in each of our test problems is: $25+40+25 \times 40+1600+1600 \times 25=2665+40,000=42,665$.

\section{Solution of Model}

Integer programs are typically hard to solve, and our primal model is no exception. This model is NP-hard (Garey and Johnson 1979) by simple extension from the uncapacitated facility location model which is known to be NP-hard. Therefore, we have used a leading industrial strength integer program optimizer CPLEX 11.2.1 (IBM ILOG CPLEX 2009) to solve the model. The implementation was conducted using ILOG's development studio for CPLEX, OPL version 6.1 (IBM ILOG OPL Development Studio 2009). The average solution time per problem in our experiment was on the order of $1 \mathrm{~min}(60 \mathrm{~s}$ ) on a PC running at $2.66 \mathrm{GHz}$ with $4 \mathrm{~GB}$ of RAM. Including setup and input-output time the average time required per problem was on the order of $5 \min$.

\section{Analysis and Results}

In this section, we discuss an extensive managerial experiment we conducted to determine the impact of important factors on the design of a hybrid retail network, and report the findings of the experiment. Specifically, we investigate the impact on system profitability of the following factors: the proportion of stores that are closed (equivalently, number of stores open given a fixed number of potential open locations), the average price sensitivity of demand, the discount offered by the online retailer, and the demand retention rate. Based upon these factors, we designed a randomized managerial experiment with the following characteristics:

(i) four factors (identified above),

(ii) two levels for the price sensitivity of demand factor (steep and moderate), 
(iii) two levels for the online discount factor (high and low),

(iv) three levels for the store proportion open factor (eight out of 40, 24 out of 40, and 36 out of 40$)$, and

(v) five levels of the demand retention rate divided equally between the online store and the nearest open store $(100 \%, 80 \%, 60 \%, 40 \%$, and $20 \%)$.

The number of open RDCs was fixed at four out of 25 potential sites throughout the experiment (The number of open RDCs was kept fixed during the analysis, but can be varied to determine the optimal number of RDCs). A treatment in this experiment was viewed as a combination of particular levels of the four factors. Thus there were 60 (i.e., $2 \times 2 \times 3 \times 5$ ) treatments in all and we solved ten randomly generated problems per treatment in the primary experiment.

In addition, the primary experiment was conducted assuming a 90\% demand retention rate at open stores after the opening of the online store with $10 \%$ of the demand shifting to the online channel. For comparison purposes, we provide additional (limited to Scenario I described below) results for a more extreme case where the open store retention rate is $45 \%$ with $55 \%$ of the demand shifting online. For Scenario I, we also provide the proportions of logistics costs allocated to the fixed, variable, inventory holding, and transportation components respectively. We provide some details regarding the cost structure of the model in Appendix A (with the understanding that this data should be taken as a disguised rather than literal representation of the cost data pertaining to the hardware chain used for our analysis).

The managerial experiment involves analyzing four major scenarios, created by combining different levels of price sensitivity of demand (steep and moderate) and online discount factor (high and low). For each of these scenarios, we determined optimal system profits for different combinations of number of open stores and demand retention rate. The total number of candidate $B M$ stores is 40 and the actual number of open stores is varied from eight to 24 to 36 . The retention rates are varied from $50 \%$ at the nearest open store and $50 \%$ at the electronics store (which amounts to full retention) to $10 \%$ at the open store and $10 \%$ at the electronic store (which amounts to a total 20\% demand retention rate). In practice, the retention rate can be obtained by surveying the customers. The results of the four scenarios are discussed below - it is seen that they have some similarities but also exhibit subtle differences.

The analysis of the first scenario is quite representative of the experiment in general, and is therefore described in detail. In this scenario, both the demand price sensitivity and the discount factor are high. The slope of the demand function varies between products from 1 to 0.5 , 
and the discount offered by the online retailer is high, varying by product from $25 \%$ to $15 \%$. For this scenario, optimal system profits are calculated for the different numbers of open stores and the different retention rates, and the results plotted in Fig. 1. We treat $100 \%$ retention rate as the benchmark solution because there is no loss of market share to the competition in this case.

For this benchmark state, savings in fixed and variable costs are achieved by closing a large number of stores. In particular, the shift in demand to the electronic store does not result in any additional holding or material handling costs (since the electronic store simply functions as an intermediary between suppliers and customers) although there are some variable costs related to the electronic operations. At the same time, the only loss of demand at this retention level stems from the change in real price to the customer. This real price is the sum of the original store price plus the cost of shipment from the online store or the cost of travel to the nearest open store plus any price differentials between a closed store and the open store to which its customers are directed. For our data, the real price faced by the customer at the surviving store is generally higher than the price the customer might have received at the closed bricks-and-mortar store. This higher price leads to a somewhat lower level of demand, but all of this lower demand is retained. As a result of these conditions, the smallest number of open stores (eight) corresponds to the highest level of profit, followed by the medium number (24) and the high number (36) respectively.

As the retention rate drops from the theoretical maximum of $100 \%$, the fixed and variable costs savings resulting from closing stores are increasingly offset by the loss of revenue from the attrition of demand. The loss of demand is from two sources, the higher full prices at both the electronic and neighboring open stores and the lower retention of demand due to factors such as inconvenience, loss of touch-and-feel, and the like. The gap in profit between low, medium, and high number of open stores begins to close as retention drops from $100 \%$ to $80 \%$ to $60 \%$ (close to which point the high and medium number of open stores essentially have the same profit level). As retention drops even further, it is seen that there is a reversal of profitability between the low and high numbers of open stores.

By interpolating slightly, it can be observed that a retention rate of about $50 \%$ represents a sort of cutoff point at which the relatively profitability of the three levels of open stores are very close. At this retention level, the losses in revenue from closing stores surpass the gains from fixed and variable cost savings. The trend continues as the level of retention drops further. While the difference in profits is not very high at $40 \%$ retention, it widens substantially at $20 \%$ retention where it clearly makes more sense to keep the high number (36) of stores open. Another observation is that while the differences in profits at the highest level of retention in this study 
(100\%) appear to be greater than the differences at the lowest level (20\%), the differences at more comparative levels (no retention versus 100\%) retention might be much smaller, given the clear trend that can be seen in the results. As a cautionary note, it is logical to expect that a very different cost structure (fixed, variable, holding, and transportation cost rates) might result in profitability gaps (between low, high, and medium number of open stores) at low retention and high retention rates that are different from our findings - as with most decision support models, specific results depend on the specific environment of the retail chain.

In the second scenario, the demand price sensitivity is set at the low level (slope of the demand function varies between 0.5 and 0.01), and the online discount level is kept at the high level (between 25\% and 15\%). Optimal system profits are again determined for different numbers of open stores and retention rates, and the results are plotted in Fig. 2. The chart for Scenario 2 shows that the results are similar to those for Scenario I, with some minor differences stemming from the fact that the flatter demand function generally favors closing a larger number of stores at higher retention rates and closing a lower number of stores at lower retention rates. While the results are generally similar to that for Scenario I, it is seen that the small number of open stores (eight) corresponds to a higher profit level at $100 \%$ retention relative to Scenario I. Similarly, the highest number of open stores (36) results in a higher profit level relative to Scenario I at $20 \%$ retention.

In the third scenario, the price sensitivity of demand is high (the slope of the demand function varies between 1 and 0.5), and the online discount level is low (varying between 10\% and 1\%). Optimal system profits are calculated as for other scenarios and plotted in Fig. 3. The transfer of demand from closed stores to neighboring open stores is at a higher full price which, given the higher price sensitivity, cuts into demand. This also applies to demand transfers to the online store and this effect is enhanced by the low online discount in this scenario. At the same time, higher full prices mean higher revenue per unit sold and the net effect is a tussle between lower units sold and higher revenue per unit. As in other scenarios, the high number of open stores (36) is associated with significantly higher fixed and variable processing costs. It is seen from Fig. 3 that, at higher retentions, it is more profitable to keep the smallest number of open stores. At lower retentions, the losses of sales from closing stores tends to, as in other scenarios, outweigh the gains from costs savings. Hence, the high number of open stores (36) is best at these retention rates. This scenario turns out to be similar in results to Scenario I except that profit is somewhat higher at the highest retention level.

Scenario IV corresponds to low price sensitivity of demand (slope of the demand function varies from 0.5 to 0.01 ) and a low level of online discount (10-1\%). This implies that full prices 
paid by customers who are switched from closed stores to the online store are higher, but the impact of the higher prices is not as severe as in Scenario 2. As a result, this configuration is a hybrid of Scenarios 2 and 3. This explains why this scenario corresponds to the highest profit levels of the four scenarios discussed above. Optimal system profits are calculated as for other scenarios and plotted in Fig. 4.

We also investigate a variant of Scenario I which we call Scenario V. This is because the model allows us to incorporate the possibility that the open store may lose some demand to the online store. It is interesting to investigate what happens when (either due to proactive financial incentives offered by the firm or a passive reaction induced by factors such as convenience of shopping) there is a significant migration of customers of open stores to the online channel, perhaps after some time has elapsed and customer awareness of the online facility has grown. In the situation we examine, $45 \%$ of customers continue to shop at open BM stores, while 55\% gravitate online. Fig. 5 shows the results for Scenario $V$ and Fig. 10 provides a side-by-side comparison of Scenario I and Scenario V.

By comparison of the two scenarios, the following results may be noted: (i) the profit levels are generally higher in the $45 \%$ retention case relative to the $90 \%$ retention case. This is due to the fact that the online facility only incurs fixed and variable costs, but not inventory holding and transportation costs (ii) the highest possible number of open stores (36) corresponds to the highest profit at all levels of retention. The rationale for this is as follows. At low levels of retention, the savings in fixed and variable costs from a low number of open stores is more than offset by the loss of revenue from lost demand. At higher levels of overall retention, the effect of the low demand retention (45\%) at open stores in Scenario $V$ has an impact which is based upon the $55 \%$ of the demand that shifts to the online facility - which, due to the absence of associated holding and transportation costs - is relatively more profitable. Since a maximum of $50 \%$ of demand of a closed store can shift to the cheaper online facility, it turns out to be more profitable to keep a store open rather than closed as long as demand only shifts internal to the company and is not lost to external competition. On the other hand, in Scenario I, even at the highest level of overall retention only $10 \%$ of the demand of an open store shifts to the less expensive online facility and thus it is more profitable to close more stores relative to Scenario $\mathrm{V}$.

To provide a representative idea of relative costs, we provide, in Figs. 6 through 9, the comparative proportions of fixed, variable, inventory holding, and transportation costs for Scenario I at the highest (100\%) and lowest (20\%) of retention of demand of closed stores. For instance, it is observed that the proportion of variable costs is highest at the full $(100 \%)$ level with the smallest number of open stores (eight). This combination corresponds to low fixed costs and 
high demand correlated with high processing (variable) costs. The other observations regarding relative proportions of the different cost components may be explained by similar analysis.

Finally, we report our findings regarding the impact on profitability of the expected number purchased parameter (enp). As defined earlier, it is the total number of items a customer is expected (on average) to purchase per shopping trip. The analysis discussed so far used an enp value of 1 , which was based on the data that was provided to us. The next step was to vary enp from 1 to 3 to 5 and observe the effect of those changes on the optimal objective value (i.e., profit level). Increasing the enp decreases the travel cost per item and hence lowers the real price to customers when they choose to shop at a nearby open store after their local store is shuttered. The expected effect of the increase in enp is an increase in transfer store demand, and with other things constant, an increase in the profit level. Our initial analysis with higher enp values indicated an increase in profit as expected, but a marginal one, on the order of $0.2 \%$ for enp $=3$ and on the order of $0.3 \%$ for enp $=5$.

This result is due to the transfer price and demand functions discussed in the section on the general model. The specific cause is the relative sizes of the travel cost (averaging about \$25 per trip), the average price of an item (about \$125), the maximum item demand per store (about 550 on average) and the price sensitivity (averaging 0.75 for high price sensitivity). Using these values for the parameters, it is straightforward to compute that the approximate decrease in demand of an item when the average travel cost burden of about $\$ 25$ is added to the average price is on the order of $4 \%$ for enp $=1$ (there is a little variation depending on the applicable retention rate). The decrease is lower when enp is increased to 3 or 5 because the travel cost premium per item becomes smaller. The relatively small decreases in demand ultimately lead to the small changes in overall profitability that are observed.

In order to determine when the enp parameter might have a bigger effect on profitability we created a hypothetical dataset based on our original data with the following modifications: maximum demand was reduced to 250 (on average), the average travel cost was increased to about $\$ 37$ per trip (\$1 per mile), and the average price was reduced to $\$ 30$. This translated to a decrease in demand per item of about $12 \%$ for enp $=1$ and somewhat smaller decreases for enp $=3$ and enp $=5$. Further computational experimentation showed that the modified data structure corresponded to profitability increases up to $1.65 \%$ for enp $=3$ and up to $2 \%$ for enp $=5$. A reassuring finding is that changing the enp from 1 to 3 or 5 did not alter the basic pattern of profitability based on the number of open stores and the prevailing retention level. Our findings for the modified dataset are summarized in Figs. 11-14. Our primary conclusion is that the impact of alternate levels of the expected number of items purchased by the customer is very 
dependent on the prevailing data structure and varies from the small (as in the case of our original dataset) to moderate (as with our modified dataset) to (possibly) significant in other cases.

\section{Concluding Remarks}

It is common in the industry for struggling retail chains to shutter some stores to alleviate high operating costs. This strategy is however fraught with implications for both the consumers and the supply chain. After a store closes, its customers may be lost forever unless they can be adequately served by another bricks-and-mortar store of the chain that stays open or by an electronic online store of the chain. However, due to travel costs, a consumer will go to another store only if the distance is not excessive. Therefore, while closing stores, the retail chain management should strive to ensure that either (i) open stores are located within reasonably accessible distances from customers of closed stores or (ii) offer an electronic alternative or (iii) a mixture of convenient open stores and an electronic store. Also, when a store closes, the supporting RDC is left with less business. If the number of stores supported by an RDC goes below a threshold level, the RDC might become economically unviable forcing it to close. This situation would create problems for the other surviving stores that have been supported by this RDC. This follows from the fact that these stores have to switch to other open RDCs, which would very likely increase the processing load and the transportation costs of the chain. These factors are taken into account in our decision support system that is designed to aid managers in determining how many (and which) stores to close.

The decision support model is an integer (specifically, binary) model. We conducted a managerial experiment to study the profitability of alternative retail network structures by varying the proportion of stores that are closed, the average price sensitivity of demand, the online discount offered by the retailer, and the demand retention rate. The most significant finding of this study is that when both the price sensitivity of demand and the online discount rate are high, it is more profitable to close a large number of stores at high retention rates and a low number of stores at low retention rates. At high retention rates, profitability rises due to savings in fixed and variable costs. However, at low retention rates, the savings due to reduction in fixed and variable costs are offset by the loss of revenue from lost customers. An interesting, and not necessarily intuitive, discovery is that when a high proportion of customers of open stores gravitate to the online channel, it may be (depending on the relative retention levels of open versus closed stores) most profitable to have as many stores open as possible under all conditions. This suggests an interesting research question: under what circumstances is it worthwhile for retail management 
to offer financial incentives to customers to migrate from BM stores to an online channel? The question is not an academic one as evidenced by the proliferation of discounts for items purchased online found in even cursory navigation of the websites of stores such as Walmart and Best Buy. Finally, we evaluated the impact of varying the expected number of items purchased per trip per customer and found that this impact is highly dependent on the specific data structure of the problem, particularly the relative magnitudes of the average price of an item and the applicable average travel cost between an open store and a closed one.

This study, in our opinion, has laid the groundwork for interesting future research involving other variants of online retailing. The most immediate model that we have in mind is one in which a retail chain enters the online channel for competitive purposes rather than as the outcome of a partial market exit strategy. The example that comes readily to mind is Blockbuster's entry into online marketing as a response to Netflix's success in marketing video rentals over the internet. It should be noted that in this case there are no planned store closings but some closings might be forced by cannibalization between the online store and bricks-and-mortar establishments. In order to avoid excessive losses due to cannibalization, the chain will probably have to conduct an aggressive (and probably costly) advertising campaign, that is, be more proactive from the beginning. Another minor variant that we are interested in is one in which there is partial market exit as in our study with the difference that the online store is set up from the beginning to aggressively fight for online market share with competing chains - in this case also, advertising and competitor's moves would play a major role. Finally, we also wish to investigate leaner supply chains which combine online retailing with not just the closing of bricks-and-mortar stores but the complete elimination of distribution centers. Our belief is that this study provides us with the foundation and framework to investigate all these models in a systematic fashion that incorporates all the important tradeoffs that come into play when a retail chain migrates to a hybrid "clicks-and-mortar" structure.

\section{References}

Aksen, Deniz and Kemal Altinkemer (2008), "A Location-Routing Problem for the Conversion to the "Click-And-Mortar" Retailing: The Static Case," European Journal of Operational Research, 186 (April (2)), 554-75.

Allaway, Arthur, J. Barry Mason and Gene Brown (1987), "An Optimal Decision Support Model for Department-Level Promotion Mix Planning," Journal of Retailing, 63 (Fall (3)), 215-42.

Ansari, Asim, Carl F. Mela and Scott A. Neslin (2008), "Customer Channel Migration," Journal of Marketing Research, XLV (February), 60-76. 
Bakos, Yannis (1997), "Reducing Buyer Search Costs: Implications for Electronic Marketplaces," Management Science, 43 (12), 1676-92.

(1998), "The Emerging Role of Electronic Marketplaces on the Internet," Communications of the ACM, 41 (8), 35-42.

Balasubramanian, Sridhar (1998), "Mail versus Mall: A Strategic Analysis of Competition between Direct Marketers and Conventional Retailers," Marketing Science, 17 (3), 18195.

Bendoly, Elliot, Doug Blocher, Kurt M. Bretthauer and M.A. Venkataramanan (2006), "Service and Cost Benefits Through Clicks-and-Mortar Integration: Implications for the Centralization/Decentralization Debate," European Journal of Operational Research, 180 (July (1)), 426-42.

Brynjolfsson, Erik and Michael D. Smith (2000), "Frictionless Commerce? A Comparison of Internet and Conventional Retailers," Management Science, 46 (4), 563-85.

Burd, Henry A. (1941), "Mortality of Men's Apparel Stores in Seattle, 1929-1939," Journal of Marketing, 6 (July (1)), 22-6.

Chiang, Wei-yu Kevin, Dilip Chhajed and James D. Hess (2003), "Direct Marketing, Indirect Profits: A Strategic Analysis of Dual-Channel Supply-Chain Design," Management Science, 49 (1), 1-20.

Chopra, Sunil and Peter Meindl (2007), "Supply Chain Management: Strategy, Planning, \& Operation," 3rd ed. Upper Saddle River, New Jersey: Pearson Prentice-Hall p. 121.

Dixit, Ashutsh and Pradeep K. Chintagunta (2007), "Learning and Exit Behavior of New Entrant Discount Airlines from City-Pair Markets," Journal of Marketing, 71 (April (2)), 150-72.

Dong, Yan, Venkatesh Shankar and Martin Dresner (2007), "Efficient Replenishment in the Distribution Channel," Journal of Retailing, 83 (August (3)), 253-78.

Drezner, Tammy (1994), "Optimal Continuous Location of a Retail Facility, Facility Attractiveness, and Market Share: An Interactive Model," Journal of Retailing, 70 (Spring (1)), 49-64.

FinancialWire (2007), "Bon-Ton to Close Distribution Center," Forest Hills, (January), 1-1.

Ganesan, Shankar, Morris George, Sandy Jap, Robert W. Palmatier and Barton Weitz (2009), "Supply Chain Management and Retailer Performance: Emerging Trends, Issues, and Implications for Research and Practice," Journal of Retailing, 85 (March (1)), 84-9.

Garey, Michael R. and David S. Johnson (1979), "Computers and Intractability: A Guide to the Theory of NP-Completeness," San Francisco: Freeman.

Greer, Howard C. (1936), "Business Mortality among Retail Meat Stores in Chicago Between 1920 and 1933," Journal of Business, 9 (July (3)), 189-20. 
Grewal, Dhruv and Michael Levy (2009), "Emerging Issues in Retailing Research," Journal of Retailing, 85 (December (4)), 522-6.

Ghosh, Avijit and C. Samuel Craig (1991), "FRANSYS: A Franchise Distribution System Location Model," Journal of Retailing, 67 (Winter (4)), 466-95.

IBM ILOG US. (2009), “CPLEX 11.2.1,” www.ilog.com, Sunnyvale, CA.

IBM ILOG US. (2009), "OPL Development Studio 6.1," www.ilog.com, Sunnyvale, CA.

Johnson, Mark S. (2000), "Causes and Consequences of US Chain Store Closings: Attributions in the Media," Psychology and Marketing, 17 (8), 721.

Karakaya, Fahri (2000), "Market Exit and Barriers to Exit: Theory and Practice," Psychology and Marketing, 17 (August (8)), 651-8.

Konus, Umut, Peter C. Verhoef and Scott A. Neslin (2008), "Multichannel Shopper Segments and their Covariates," Journal of Retailing, 84 (December (4)), 398-413.

Kwon, Wi-Suk and Sharron J. Lennon (2009), "Reciprocal Effects between Multichannel Retailers' Offline and Online Brand Images," Journal of Retailing, 85 (September (3)), 376-90.

Laroche, Michel, Zhiyong Yang, Gordon H.G. McDougall and Jasmin Bergeron (2005), "Internet versus Bricks-and-Mortar Retailers: An Investigation into Intangibility and its Consequences," Journal of Retailing, 81 (4), 251-67.

McGarry, Edmund D. (1947), "The Mortality of Independent Grocery Stores in Buffalo and Pittsburgh, 1919-1941," Journal of Marketing, 12 (July (1)), 14-2.

Murto, Pauli (2004), "Exit in Duopoly under Uncertainty," The Rand Journal of Economics, 35 (Spring (1)), 111-28.

Pentina, Iryna, Lou E. Pelton and Ronald W. Hasty (2009), "Performance Implications of Online Entry Timing by Store-Based Retailers: A Longitudinal Investigation," Journal of Retailing, 85 (June (2)), 177-89.

Phillips, Charles F. (1934), "Chain Store Mortality," Journal of Business, 7 (4), 318-27.

Ping S Robert A. Jr. (1999), "Unexplored Antecedents of Exiting in a Marketing Channel," Journal of Retailing, 75 (Summer (2)), 218.

Simchi-Levi, David, Philip Kaminsky and Edith Simchi-Levi (2007), "Designing and Managing the Supply Chain: Concepts, Strategies and Case Studies," 3rd ed. New York, NY: McGraw-Hill Irwin p. 79

Smith, Stephen A., Narendra Agrawal and Shelby H. Mclntyre (1998), "A Discrete Optimization Model for Seasonal Merchandise Planning," Journal of Retailing, 74 (Summer (2)), 193221.

Syam, Bhatnagar 21 
Star, Alvin D. and Michael Z. Massel (1981), "Survival Rate for Retailers," Journal of Retailing, 57 (2), 87-99.

Tang, Fang-Fang Tang and Xiaolin Xing (2001), "Will the Growth of Multichannel Retailing Diminish the Pricing Efficiency of the Web?," Journal of Retailing, 77 (Fall (3)), 319-31.

Wallace, David W., Joan L. Giese and Jean L. Johnson (2004), "Customer Retailer Loyalty in the Context of Multiple Channel Strategies," Journal of Retailing, 80 (4), 249-63. 


\section{Appendix A. Data for Primary Results}

Note: All the data are uniformly distributed within the ranges shown, unless stated otherwise.

Price: U(\$50, \$200), Demand: U(100, 1000), Fixed Cost/unit: U(\$16, \$18), Weight: $\mathrm{U}(10 \mathrm{lbs}, 100 \mathrm{lbs})$.

Transportation cost/mile/pound: $\mathrm{U}(\$ 0.001, \$ 0.003)$, Variable Cost $\% /$ unit value: $U(45 \%$, 50\%), Inventory holding Cost \%/unit value: $U(8 \%, 10 \%)$.

Online shipping charge\%/unit value: $U(5 \%, 10 \%)$, Travel surcharge/mile: $U(\$ 0.3, \$ 1)$, Variable Cost $\%$ online/unit value: U(50\%, 60\%).

Online facility fixed cost: $\$ 8,000,000$. 


\section{Exhibit 1}

Image unavailable due to third-party copyright restrictions. Please see definitive

published version to view image: http://dx.doi.org/10.1016/j.jretai.2010.05.001

Syam, Bhatnagar 24 
Figure 1: Profit under Scenario 1

Demand Price Sensitivity: High and Discount Factor: High

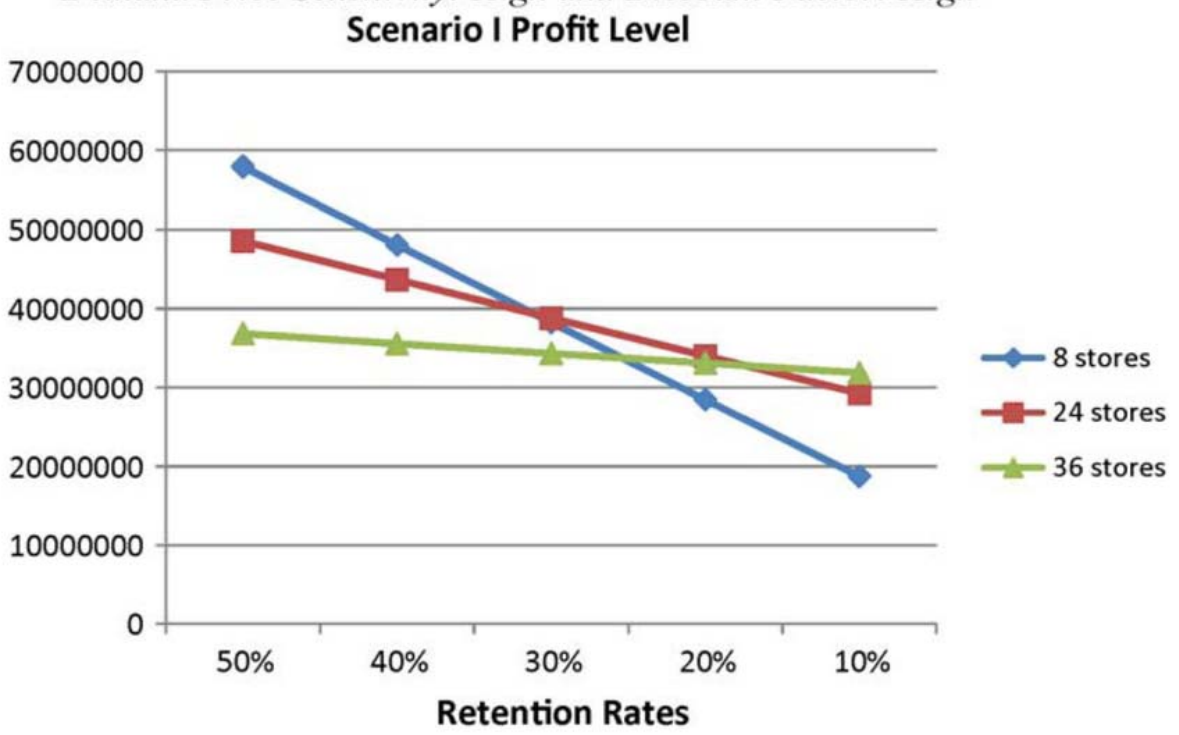


Figure 2: Profit under Scenario 2

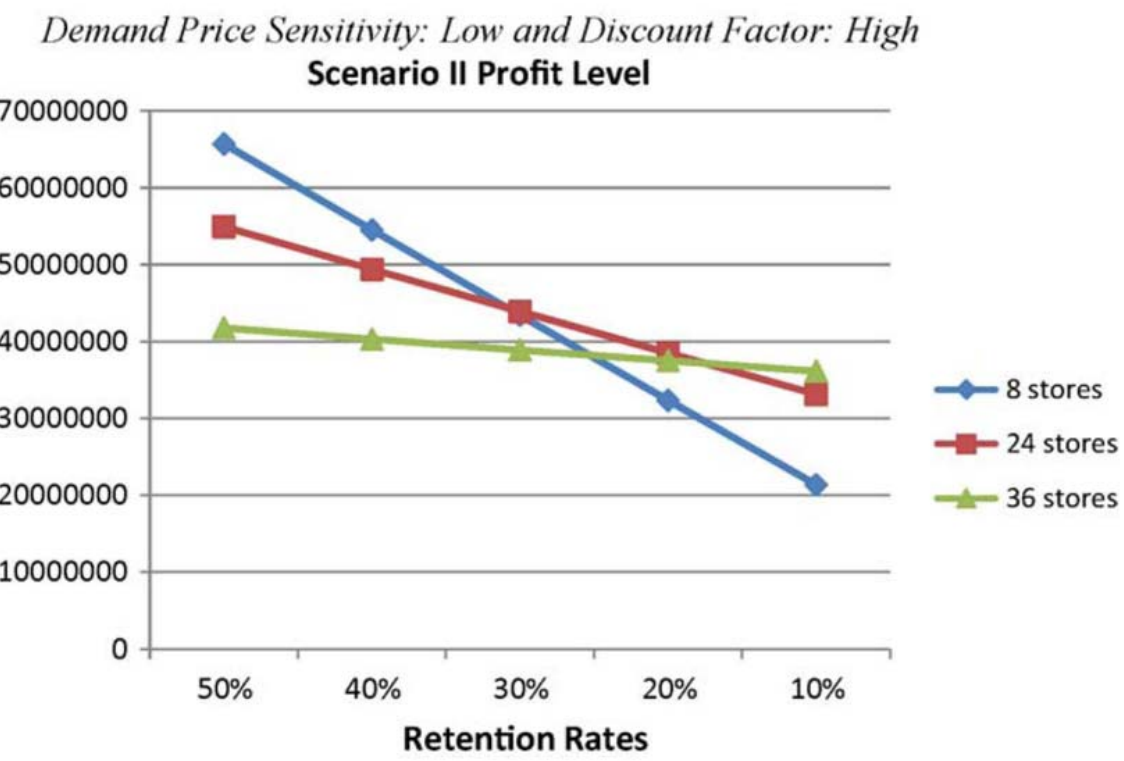


Figure 3: Profit under Scenario 3

Demand Price Sensitivity: High and Discount Factor: Low

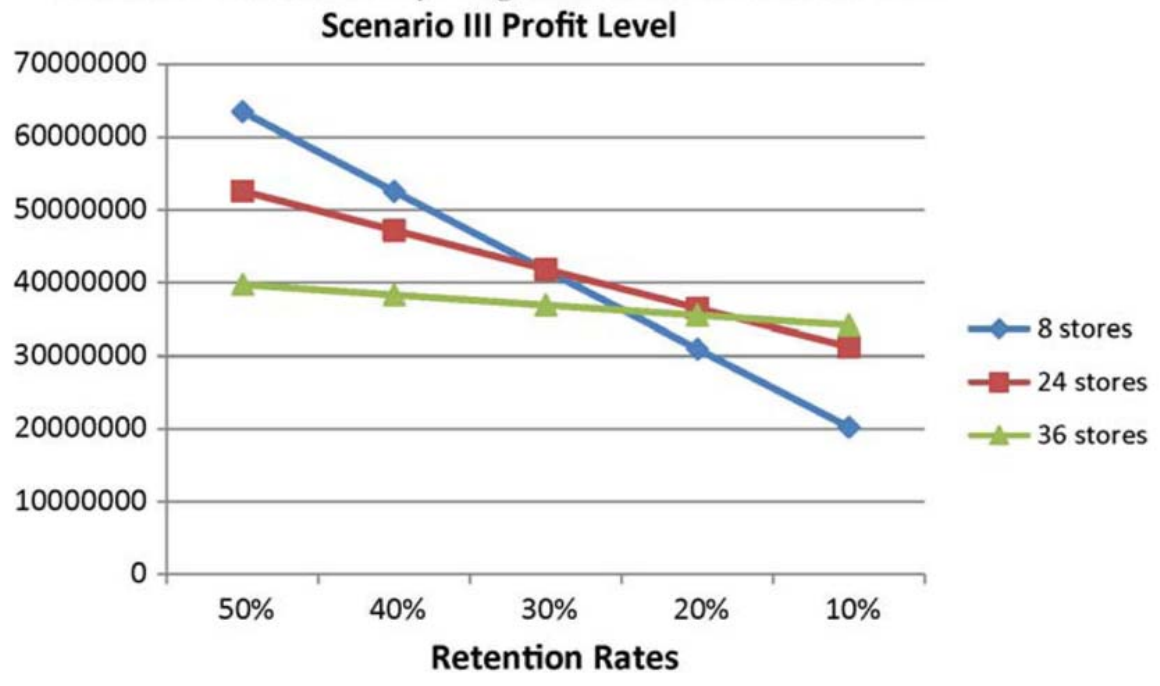


Figure 4: Profit under Scenario 4

Demand Price Sensitivity: Low and Discount Factor: Low

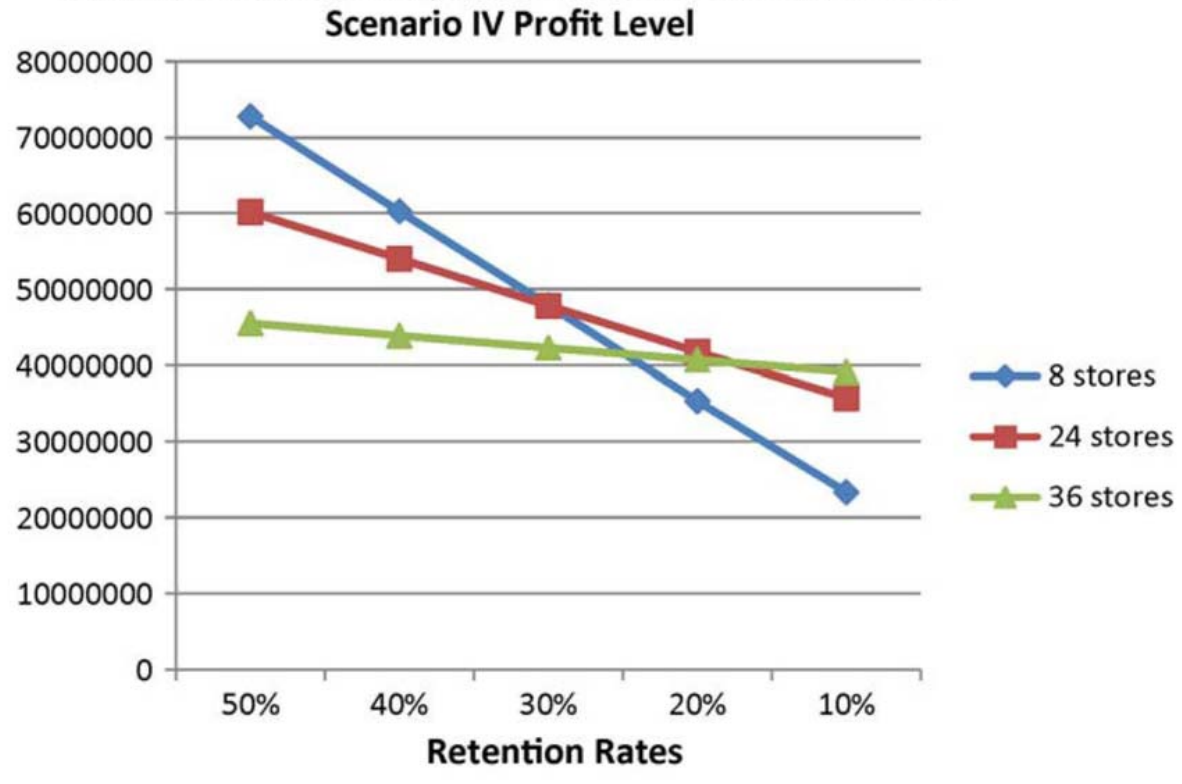


Figure 5: Profit under Scenario 1, 45\% retention at open stores

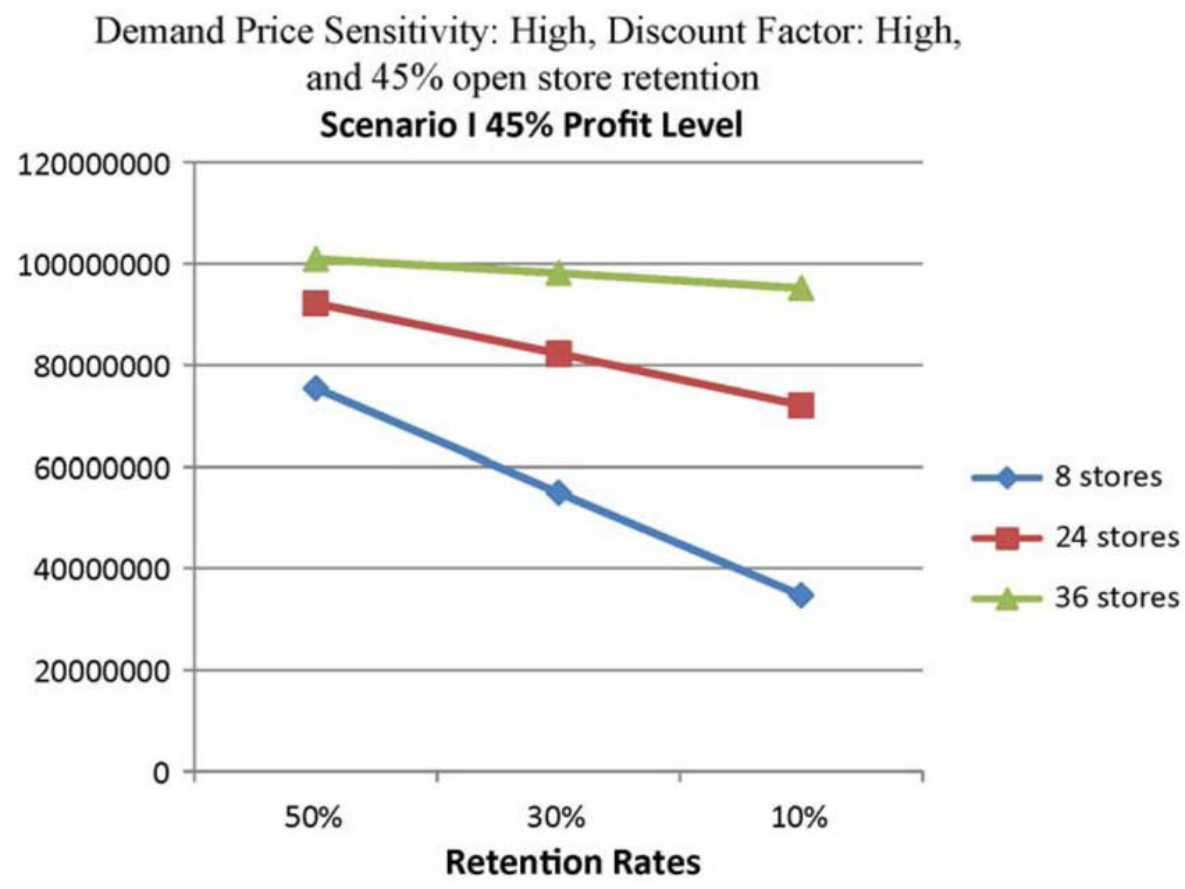


Figure 6: Cost Proportions under Scenario 1: Fixed Costs

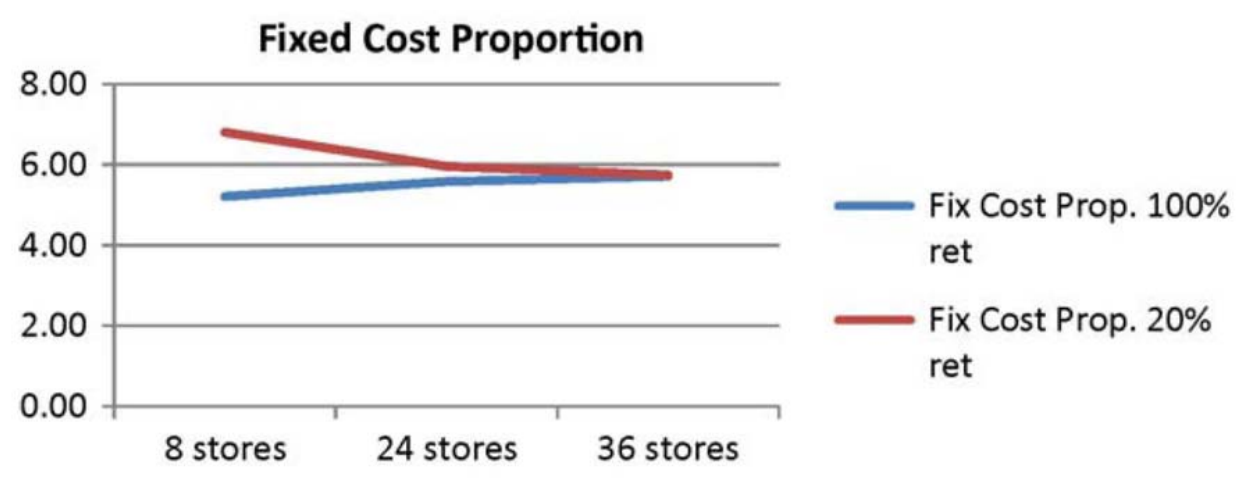


Figure 7: Variable Cost Proportion under Scenario 1

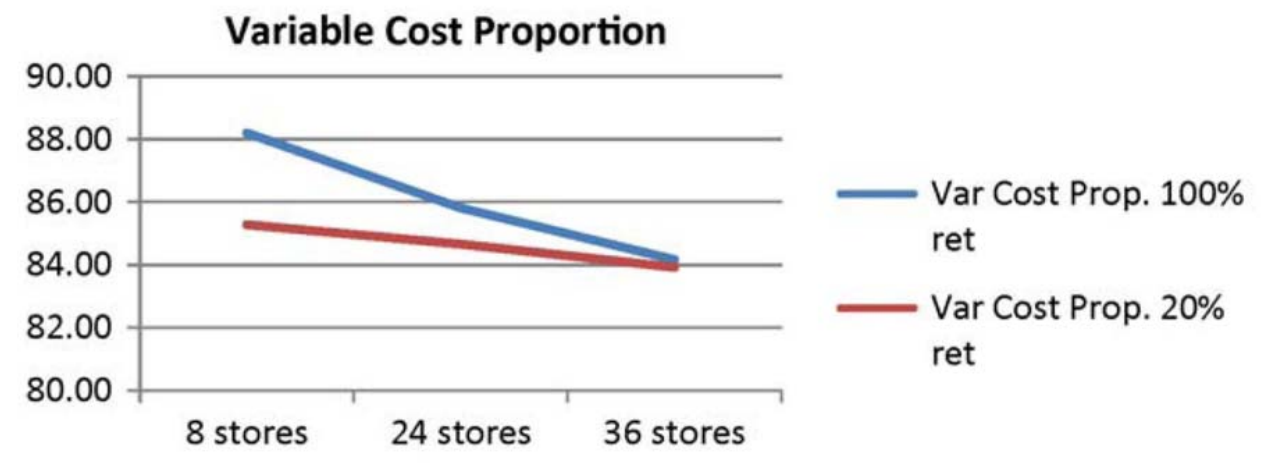


Figure 8: Holding Cost Proportion under Scenario 1

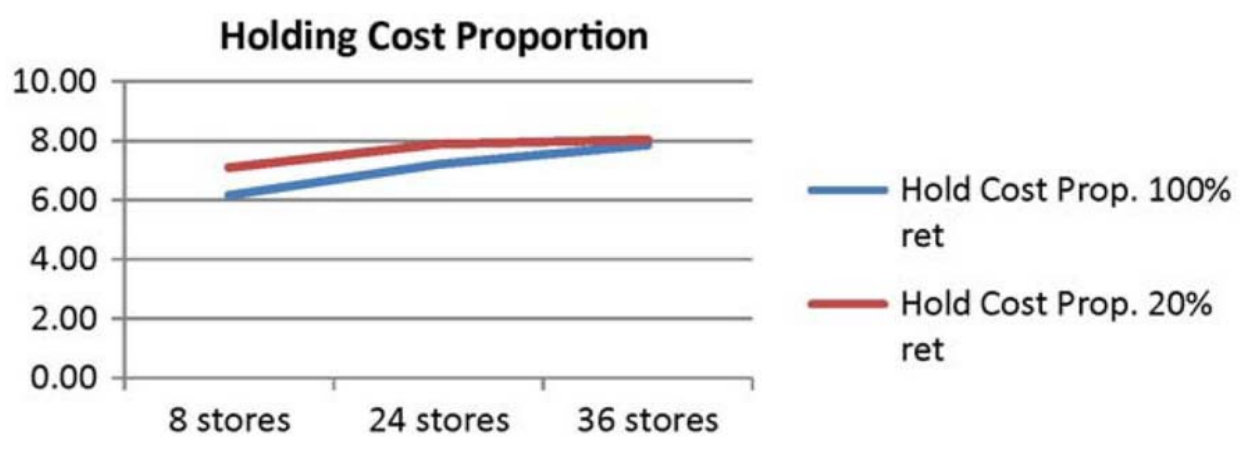


Figure 9: Transportation Cost Proportion under Scenario 1

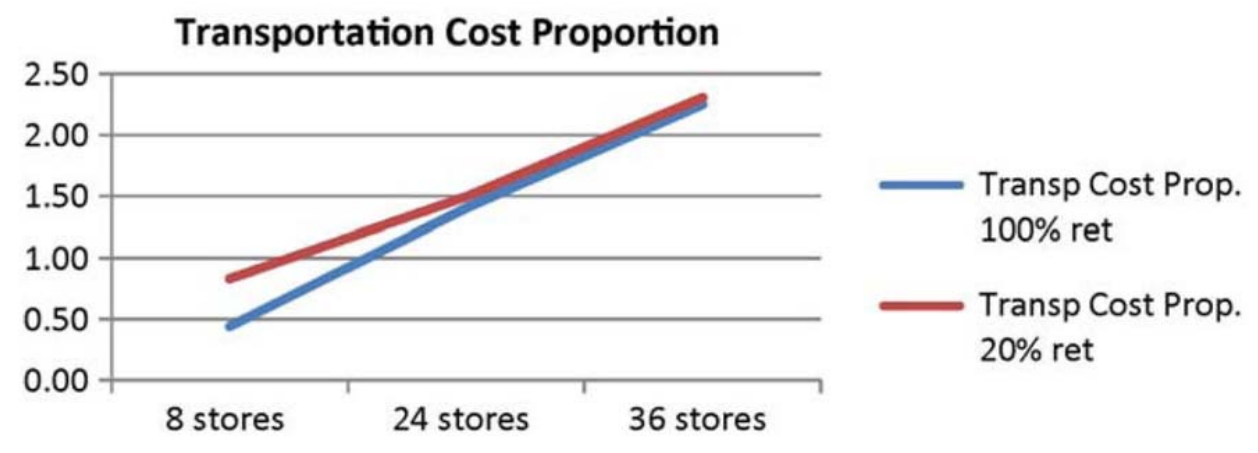


Figure 10: Scenario 1: $90 \%$ versus 45\% Open Store Retention

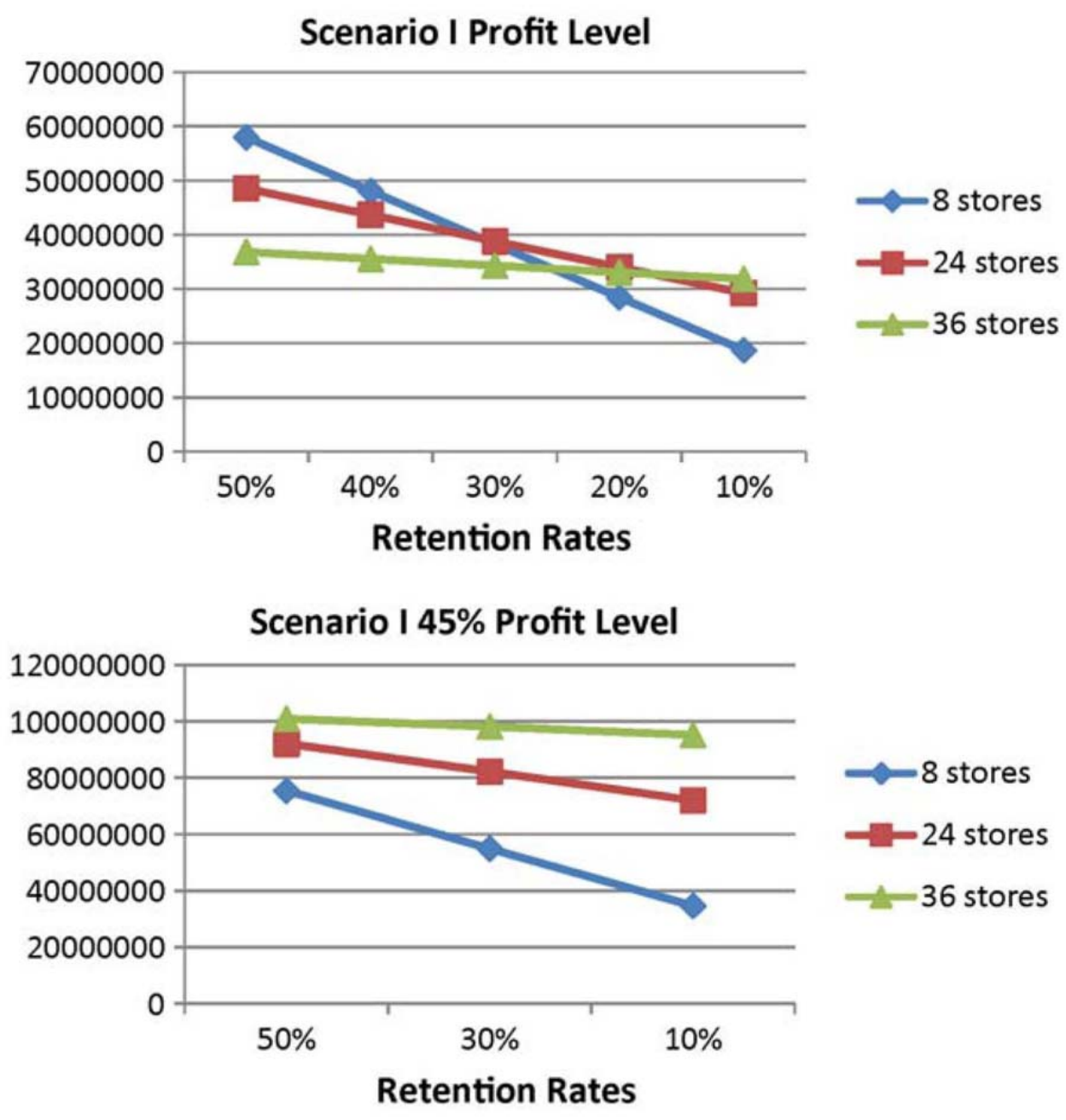


Figure 11: Percentage Increase in Optimal Objective Value (Modified Data, enp = 3)

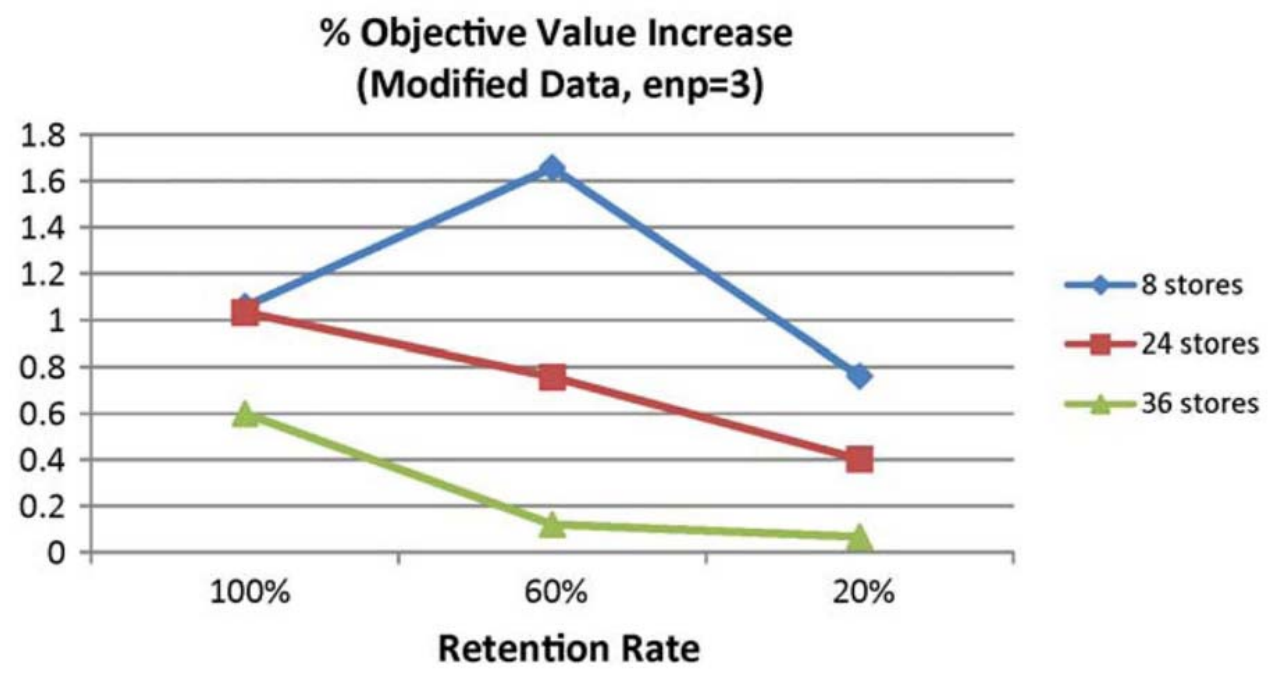


Figure 12: Percentage Increase in Optimal Objective Value (Modified Data, enp = 5)

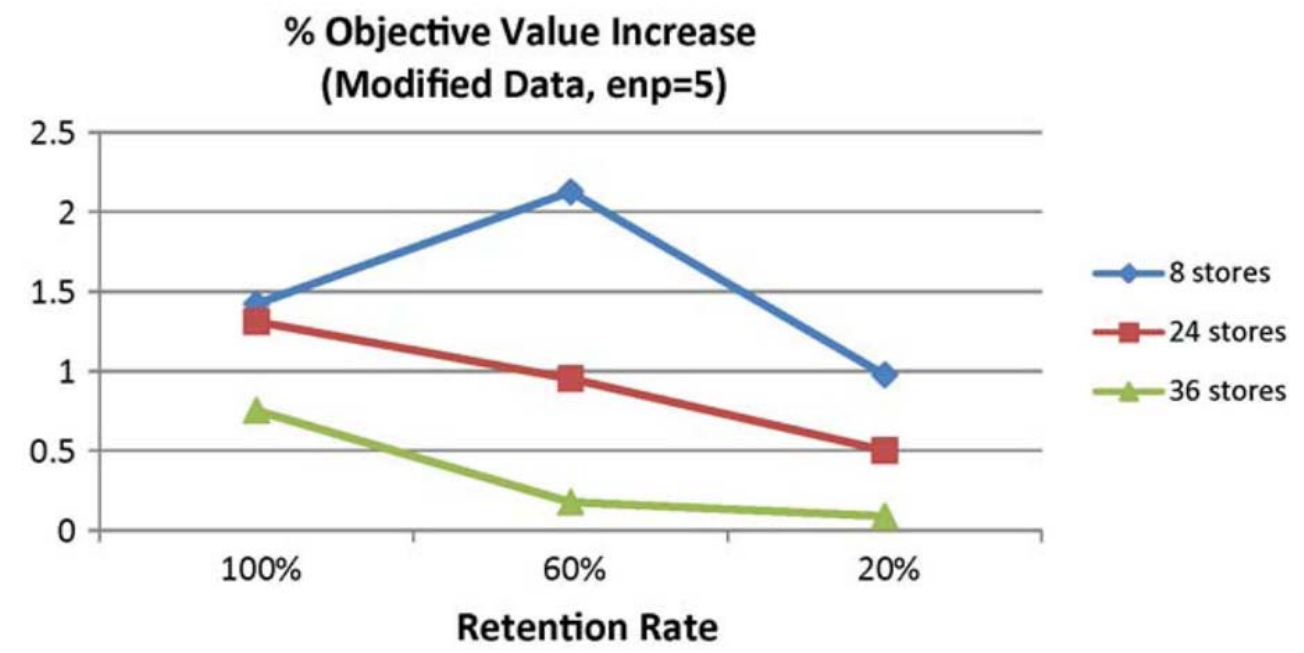


Figure 13: Profit by Number of Open Stores and Retention Levels (Scenario I, modified data, enp = 3)

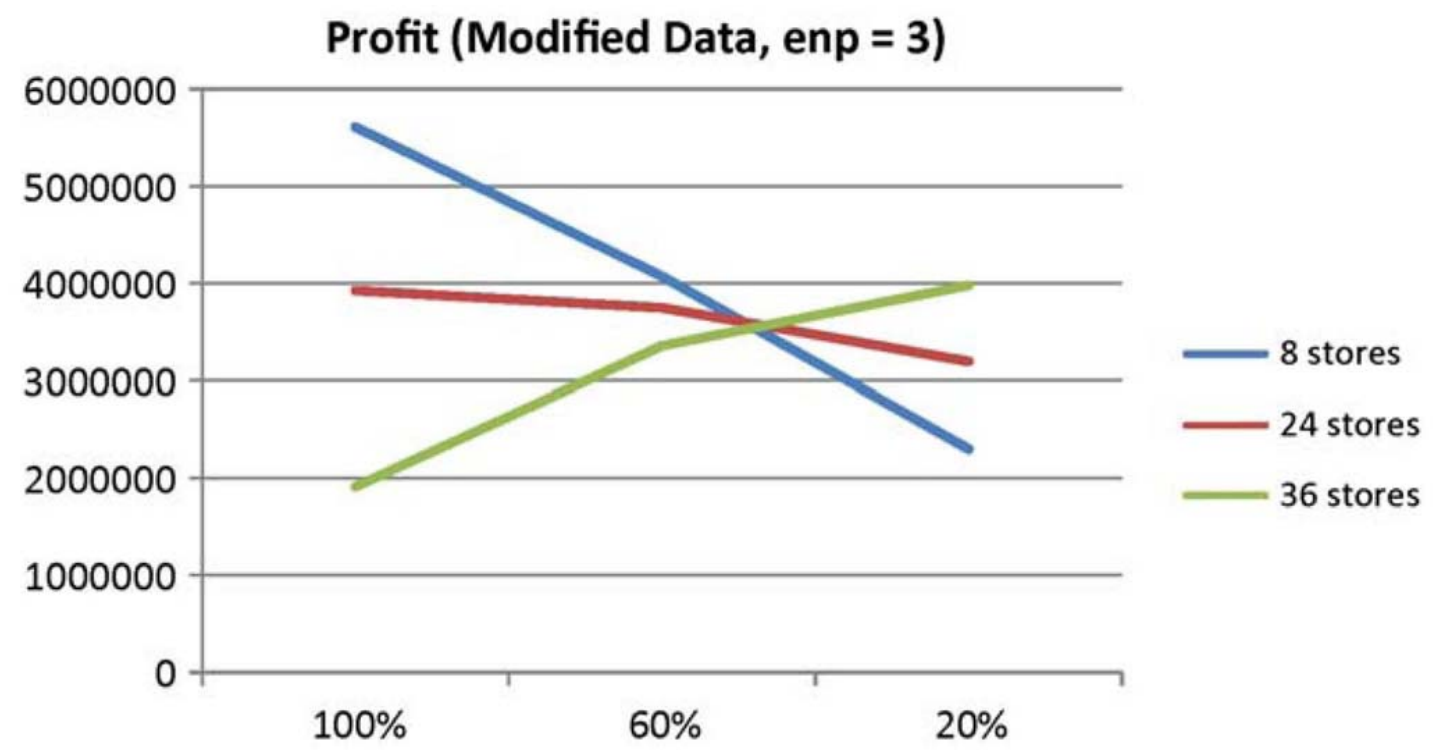


Figure 14: Profit by Number of Open Stores and Retention Levels (Scenario I, modified data, enp = 5)

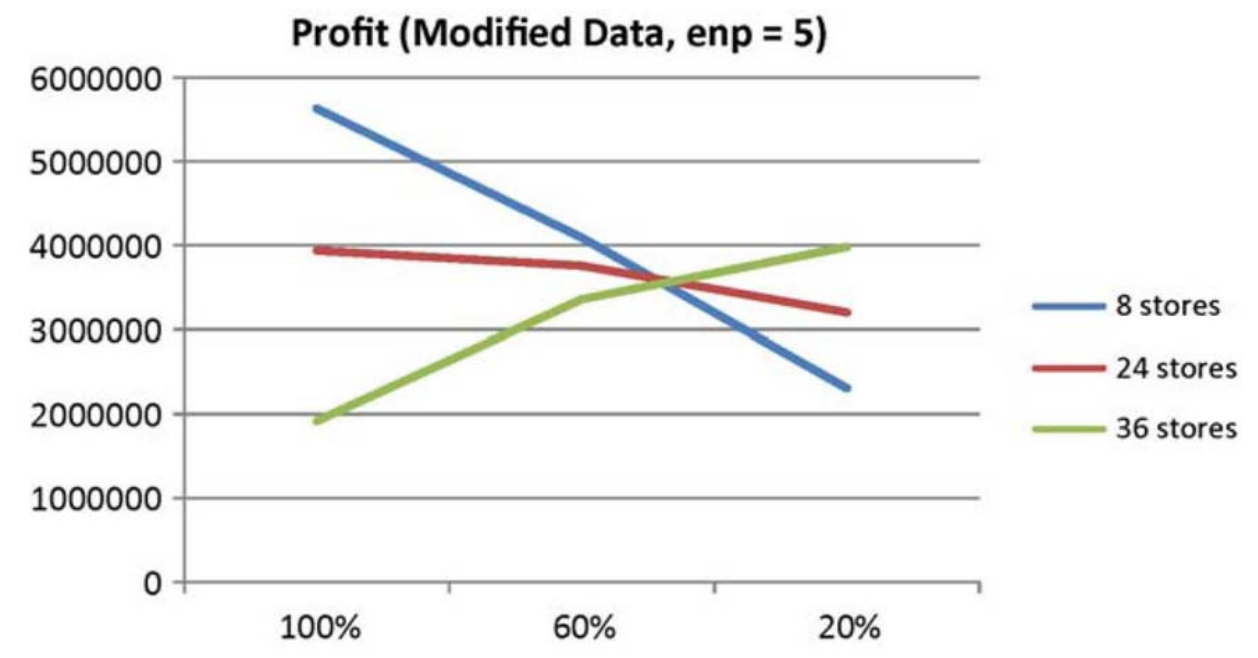




\section{Table 1}

\begin{tabular}{|c|c|}
\hline \multicolumn{2}{|c|}{ Decision variables } \\
\hline$\alpha_{m}:$ & $\begin{array}{l}0-1 \text { binary variable equal to } 1 \text { if } \mathrm{RDC} m \text { is open, } 0 \\
\text { otherwise }\end{array}$ \\
\hline$\beta_{n}:$ & $\begin{array}{l}0-1 \text { binary variable equal to } 1 \text { if } \mathrm{BM} \text { store } n \text { is open, } 0 \\
\text { otherwise }\end{array}$ \\
\hline$\gamma_{m n}:$ & $\begin{array}{l}0-1 \text { binary variable equal to } 1 \text { if } \mathrm{BM} \text { store } n \text { is assigned } \\
\text { to RDC } m, 0 \text { otherwise }\end{array}$ \\
\hline$\varphi_{k n}:$ & $\begin{array}{l}0-1 \text { binary variable equal to } 1 \text { if closed store } k \text { is } \\
\text { assigned to open store } n\end{array}$ \\
\hline$\omega_{k m n}:$ & $\begin{array}{l}0-1 \text { binary variable equal to } 1 \text { if closed store } k \text { is } \\
\text { assigned to open store } n \text { which is assigned to RDC } m\end{array}$ \\
\hline \multicolumn{2}{|r|}{${ }^{-}$} \\
\hline$\pi^{o}:$ & Online store retention factor \\
\hline$\pi^{k}:$ & Closed store $k$ retention factor \\
\hline$\pi^{n}:$ & Open store $n$ retention factor \\
\hline$\pi^{m}:$ & Open RDC $m$ retention factor \\
\hline$d_{i n}:$ & Current demand for item $i$ at BM store $n$ \\
\hline$d_{i m}:$ & Demand for item $i$ at RDC $m$ (if sale permitted) \\
\hline$d_{i}^{k o}:$ & $\begin{array}{l}\text { Demand for item } i \text { that is transferred to online store } \\
\text { from closed store } k\end{array}$ \\
\hline$d_{i}^{n o}:$ & $\begin{array}{l}\text { Demand for item } i \text { that is transferred to online store } \\
\text { from open store } n\end{array}$ \\
\hline$d_{i}^{k n}:$ & $\begin{array}{l}\text { Demand for item } i \text { that is transferred to open BM store } n \\
\text { from closed store } k\end{array}$ \\
\hline$m d_{m}:$ & Demand modification factor at RDC $m$ \\
\hline$p_{\text {in }}:$ & Price of item $i$ at open BM store $n$ \\
\hline$p_{i m}:$ & Price of item $i$ at RDC $\mathrm{m}$ (if sales are permitted) \\
\hline$p_{i k}:$ & Price of item $i$ at closed store $k$ \\
\hline$p_{i}^{k n}:$ & $\begin{array}{l}\text { Full price of item } i \text { at open BM store } n \text { for customers of } \\
\text { closed BM store } k\end{array}$ \\
\hline$p_{i}^{o}:$ & Full price of item $i$ at online store \\
\hline$s c_{i}:$ & $\begin{array}{l}\text { Shipping charge for item } i \text { at online store expressed as } \\
\text { percent of price }\end{array}$ \\
\hline$o d c_{i}$ & $\begin{array}{l}\text { Price discount for item } i \text { at online store expressed as } \\
\text { percent of price }\end{array}$ \\
\hline$t s^{k n}:$ & $\begin{array}{l}\text { Travel surcharge from closed BM store } k \text { to open BM } \\
\text { store } n\end{array}$ \\
\hline enp: & Expected number of purchases per customer per trip \\
\hline$F C_{o}:$ & Fixed overhead cost at online store \\
\hline$v c_{o}:$ & Variable cost as percent of price at online store \\
\hline$F C_{m}:$ & Fixed overhead cost at RDC $m$ \\
\hline$v c_{m}:$ & Variable cost as percent of price at RDC $m$ \\
\hline$e f_{m}:$ & Cost efficiency factor at RDC $m$ \\
\hline$F C_{n}:$ & Fixed overhead cost at BM store $n$ \\
\hline$v c_{n}:$ & Variable cost as percent of price at store $n$ \\
\hline$h c_{i}:$ & Holding cost as percent of price for item $i$ \\
\hline dist $_{m n}$ : & Distance in miles between RDC $m$ and BM store $n$ \\
\hline$t c_{i}:$ & Transportation cost per mile per pound for item $i$ \\
\hline$w t_{i}:$ & Weight per pound of item $i$ \\
\hline$d s l p_{i}:$ & Slope of demand function for item $i$ \\
\hline$d m x_{i}$ & Maximum possible demand for item $i$ at any store \\
\hline DistRB: & $\begin{array}{l}\text { Distance limit between RDC } m \text { and BM store } n \text { assigned } \\
\text { to RDC } m\end{array}$ \\
\hline DistCB: & $\begin{array}{l}\text { Distance limit between open BM store } n \text { and closed BM } \\
\text { store } k \text { assigned to store } n\end{array}$ \\
\hline NCLS: & Number of closed stores \\
\hline NODC: & Number of open RDCs \\
\hline
\end{tabular}

